\title{
TNF $\alpha$-induced GM-CSF release from human airway smooth muscle cells depends on activation of an ET-1 autoregulatory positive feedback mechanism
}

\author{
J Knobloch, ${ }^{1}$ H Peters,' D Jungck, ${ }^{1}$ K Müller, J Strauch, ${ }^{2}$ A Koch'
}

- Additional details of the methods and results, and an additional figure are published online only at http://thorax.bmj. com/content/vol64/issue12

${ }^{1}$ Department of Pneumology, Clinic III for Internal Medicine, University of Cologne, Cologne Germany; ${ }^{2}$ Heart \& Thoracic Surgery, University of Cologne, Cologne, Germany

Correspondence to: Dr A Koch, Department of Pneumology, Clinic III for Internal Medicine, University of Cologne, Kerpener Str. 62, D-50937

Cologne, Germany;

andrea.koch@uk-koeln.de

Received 12 November 2008 Accepted 16 September 2009 Published Online First 22 October 2009

\begin{abstract}
Background: There is an urgent need to inhibit endothelin-1 (ET-1) induced chronic inflammatory processes in early stages of lung diseases in order to prevent untreatable irreversible stages often accompanied by lung fibrosis and pulmonary hypertension. Nothing is known about the airway inflammation-inducing and/or maintaining role of ET-1 in human airway smooth muscle cells (HASMCs).
\end{abstract}

Objective: ET-1 and granulocyte-macrophage colonystimulating factor (GM-CSF) expression in response to tumour necrosis factor $\alpha$ (TNF $\alpha$ ) and ET-1 stimulation was investigated, and the impact of mitogen-activated protein kinase (MAPK) pathways in this context was studied. To elucidate the anti-inflammatory properties of the dual endothelin receptor antagonist bosentan that targets both endothelin receptor subtypes $A\left(E T_{A} R\right)$ and $B\left(E T_{B} R\right)$, its effect on the TNF $\alpha / E T-1 / G M-C S F$ network was investigated.

Methods: ET-1 and GM-CSF expression and activation of MAPKs were investigated via quantitative reverse transcription-PCR (RT-PCR), western blotting and ELISA.

Main results: Both TNF $\alpha$ and ET-1 activated p38 $8^{\text {MAPK }}$ and extracellular signal-regulated kinase (ERK)-1/-2 signalling. ET-1 expression was induced by TNF $\alpha$ and by ET-1 itself. Both effects were inhibited by bosentan and by specific $\mathrm{ET}_{\mathrm{A}} \mathrm{R}$ or p38MAPK blockade. ET-1- and TNF $\alpha$-induced GMCSF expression were both reduced by bosentan as well as by specific inhibition of either $E_{A} R, E T_{B} R, p 38^{\text {MAPK }}$ or ERK-1/-2.

Conclusion: TNF $\alpha$ activates an $\mathrm{ET}_{\mathrm{A}} \mathrm{R}$ - and $\mathrm{p} 38^{\mathrm{MAPK}}$ dependent ET-1 autoregulatory positive feedback loop to maintain GM-CSF release from HASMCs. Since bosentan impairs ET-1 autoregulation and TNF $\alpha$-induced ET-1 release, as well as TNF $\alpha$ - and ET-1-induced GM-CSF release, the present data suggest therapeutic utility for bosentan in treating particularly the early stages of chronic inflammatory airway diseases.

Airway smooth muscle cells (ASMCs) are believed to play a critical role in the establishment of inflammation in chronic inflammatory airway diseases and also in pulmonary fibrosis for which current literature suggests airway inflammation as an important factor for disease genesis and progression. ${ }^{12}$ An inflammatory environment can induce ASMCs to secrete chemokines, cytokines and growth factors. Hence, ASMCs are suggested to perpetuate inflammation within the airway wall by promoting recruitment, activation and trafficking of inflammatory cells. ${ }^{1}$ This can lead to airway wall and airway vessel remodelling, which is understood as the main cause of irreversible airway obstruction or pulmonary hypertension of patients with chronic inflammatory airway diseases. ${ }^{3}$ Thus, the therapeutic counter-regulation of inflammatory mechanisms of ASMCs might be an auspicious strategy to combat airway inflammationassociated diseases in early reversible stages.

Chronic inflammatory airway diseases and pulmonary fibrosis are characterised by elevated tumour necrosis factor $\alpha$ (TNF $\alpha$ ) levels in sputum or bronchoalveolar lavage fluid (BALF), indicating a central role for $\mathrm{TNF} \alpha$ in the establishment and/or maintenance of pathogenesis. ${ }^{4-6}$ As TNF $\alpha$ is believed to act as an initiating cytokine in airway inflammation regulating infiltration/recruitment of immune effector cells into the lung, ${ }^{7} \mathrm{TNF} \alpha-$ mediated processes are of interest in terms of therapeutically intervening airway inflammation at early disease stages. TNF $\alpha$ signals through TNF receptors 1 and 2 (TNFR1 and 2) which both are expressed on human ASMCs (HASMCs). ${ }^{8}$

In ASMCs, TNF $\alpha$ induces the release of granulocyte-macrophage colony-stimulating factor (GM-CSF). ${ }^{9}$ GM-CSF is a proinflammatory and profibrotic cytokine with key functions in the establishment of airway inflammation, ${ }^{10}{ }^{11}$ and recent studies predict therapeutic utility for GMCSF neutralisation in chronic inflammatory airway diseases and pulmonary fibrosis. GM-CSF deficiency/neutralisation impairs airway inflammation in murine models of allergic asthma and chronic obstructive pulmonary disease (COPD). ${ }^{12-14}$ GMCSF is increased in the BALF of patients with pulmonary fibrosis, stimulates macrophages to release profibrotic cytokines and might induce fibrosis by direct stimulation of ASMCs. ${ }^{10}$

Endothelin-1 (ET-1), a secreted peptide, signals through $\mathrm{ET}_{\mathrm{A}}$ and $\mathrm{ET}_{\mathrm{B}}$ transmembrane receptors $\left(E T_{A} R\right.$ and $\left.E T_{B} R\right)$, both belonging to the G-protein superfamily, and both are expressed on HASMCs. ${ }^{15}$ Activation of the ET-1 gene leads to the release of big-ET-1, an inactive ET-1 precursor extracellularly processed into active ET-1 (hereafter referred to as ET-1). ${ }^{16}$ Accumulating evidence is indicating the role of ET-1 as a proinflammatory cytokine. ET-1 is known to prime neutrophils, activate mast cells and stimulate monocytes to produce a variety of proinflammatory cytokines. ${ }^{16}$ The hypothesis that ET-1 might contribute to airway inflammation in chronic inflammatory airway diseases finds support from studies demonstrating increased ET-1 levels in exhaled breath condensates of patients with asthma (in correlation with disease severity) and in sputum of patients with COPD. ${ }^{17}{ }^{18}$ ET-1 also has profibrotic properties and its levels are 
elevated in sputum, BALF and fibrotic tissue of patients with cystic or idiopathic pulmonary fibrosis (IPF). ${ }^{17}{ }^{19}$ ET-1 is abundantly expressed in the vascular endothelium of the lung and, to a lesser extent, by other cell types, including pulmonary artery smooth muscle cells and lung fibroblasts. ${ }^{20}$ Whereas many studies have focused on the effects of ET-1 on vascular smooth muscle cells, ${ }^{20}$ there is no information about ET-1 expression in HASMCs and the ASMC inflammatory response to ET-1 stimulation.

Bosentan, approved as a treatment for pulmonary arterial hypertension combating vasoconstriction, is an endothelin receptor antagonist with almost equal affinity for $\mathrm{ET}_{\mathrm{A}} \mathrm{R}$ and $E T_{B} R$, and thus commonly referred to as a dual blocker. ${ }^{20}$ Concerning the inflammatory and profibrotic properties of ET-1, bosentan might also be useful as a treatment for chronic inflammatory airway diseases and pulmonary fibrosis in early disease stages. In rat models of emphysema and eosinophilic airway inflammation, application of bosentan results in a decrease of inflammation due to a substantial reduction in leucocyte number and/or a decrease in the level of proinflammatory cytokines in the BALF and in lung tissue. ${ }^{21} 22$

The aim of this study was to elucidate for the first time the expression and inflammatory properties of ET-1 in HASMCs. To this end, we investigated ET-1 expression in response to TNF $\alpha$ stimulation. Since secreted inflammatory factors have been known temporarily to induce their own expression to potentiate inflammation rapidly (autoregulatory positive feedback mechanism), we investigated the autoregulation of ET-1 expression in cultured HASMCs. We studied the release of GM-CSF in response to TNF $\alpha$ and ET-1. To elucidate the anti-inflammatory properties of bosentan in HASMCs, we studied its effect on the TNF $\alpha /$ ET-1/ GM-CSF network. Finally, we investigated the impact of endothelin receptor subtypes and mitogen-activated protein kinase (MAPK) pathways in these processes.

\section{METHODS}

\section{Isolation and cultivation of HASMCs}

HASMCs were dissected from lobar or main bronchus tissue obtained from patients undergoing lung resection as previously described. ${ }^{23}$ Cultivation and characterisation of HASMCs was performed as described elsewhere. ${ }^{24}$ For details see the Supplementary online material.

\section{Stimulation of HASMCs}

Before stimulation, subconfluent cell monolayers were deprived of serum for $24 \mathrm{~h}$ as previously described. ${ }^{24}$ Details of the media used for serum withdrawal and stimulation are given in the Supplementary online material. HASMCs were stimulated with ET-1 (Sigma, Hamburg, Germany; catalogue no. E7764) at $100 \mathrm{nM}$ or with human TNF $\alpha$ (R\&D systems, Minneapolis, Minnesota, USA; catalogue no. 210-TA) at $20 \mathrm{ng} / \mathrm{ml}$ for the indicated times. Bosentan (Actelion Pharmaceuticals, Freiburg, Germany), BQ123 (Sigma; catalogue no. B150) or BQ788 (Sigma; cat catalogue no. B157) were added at $10^{-6} \mathrm{M}$ or at the indicated concentrations 60 or $120 \mathrm{~min}$ before ET-1 or TNF $\alpha$ stimulation, respectively. Pretreatment with monoclonal blocking antibodies to TNFR1 (clone H398; Alexis, Lausen, Switzerland; catalogue no. ALX-804-200) and TNFR2 (clone 80M2; Alexis; catalogue no. ALX-804-450) each at $10 \mu \mathrm{g} / \mathrm{ml}$ or with PD098059 (10 $\mu \mathrm{M}$; Calbiochem/VWR, Darmstadt, Germany; catalogue no. 513000) and SB203580 (10 $\mu \mathrm{M}$, Calbiochem/VWR; catalogue no. 559389) was carried out 60 or $30 \mathrm{~min}$ before stimulation, respectively.

\section{Semi-quantitative reverse transcription-PCR (RT-PCR)}

RNA was isolated with the RNeasy spin column chromatography (Qiagen, Hilden, Germany) according to the instructions of the manufacturer. Semi-quantitative RT-PCR for ET-1 and GM-CSF (with PCR cycle conditions to analyse the output in the linear range) was performed as described before. ${ }^{25}$ Glyceraldehyde phosphate dehydrogenase (GAPDH) was used as a standard. PCR conditions and primer sequences are given in the Supplementary online material.

\section{Enzyme-linked immunosorbent assays}

Quantitative ELISAs for GM-CSF, ET-1 or big-ET-1 were done with supernatants of subconfluent HASMCs on a 6-well plate. Intracellular ELISA for phosphorylated (active) p38MAPK with total p38MAPK as a reference was carried out on subconfluent HASMCs on a 96-well plate. GM-CSF ELISA was performed as described before. ${ }^{26}$ ET-1, big-ET-1 (Biomedica, Vienna, Austria; catalogue nos BI-20052 and BI-20082) and phosphorylated p38MAPK ELISAs (R\&D Systems; catalogue no. KBC869) were performed according to the instructions of the manufacturer. ELISA protocols are given in the Supplementary online material.

\section{Western blotting}

Protein extraction from HASMCs and immunodetection of phosphorylated (active) extracellular signal-regulated kinase (ERK)-1/-2 and of GAPDH were performed as previously described. ${ }^{24}$ Details are given in the Supplementary online material.

\section{Statistical analysis}

Statistical analyses were performed to examine the effects of TNF $\alpha$ and ET-1 alone or in combination with enzyme inhibitors on gene transcription, enzyme activation and cytokine release by HASMCs. The Gaussian distribution for each data set was confirmed by histogram analyses and Kolmogorov-Smirnov test. Results are expressed as mean (SEM). Comparisons over time or across different stimulations on matched HASMC samples of one subject for $\mathrm{n}$ independent subjects were analysed by one-way repeated measures analysis of variance (ANOVA) with $95 \%$ CIs. For separate comparisons of each stimulation, post hoc Bonferroni-Holm tests were performed. A p value $<0.05$ was considered as statistically significant.

\section{RESULTS}

\section{ET-1 induces its own expression in HASMCs via $\mathrm{ET}_{A} R$ and p38 ${ }^{\text {MAPK }}$}

In dose-repsonse and time-response experiments ET-1 induced its own transcription in HASMCs at the highest level ( $\sim 3$-fold above the unstimulated control) at $100 \mathrm{nM}$ after $2 \mathrm{~h}$ of stimulation (fig 1A,B). These conditions were used in the subsequent experiments. Notably, the ET-1-inducing effect on ET-1 transcription was maintained for $8 \mathrm{~h}$ (fig 1B). A minimum concentration of $10^{-6} \mathrm{M}$ bosentan was required to block ET-1induced ET-1 transcription almost completely (fig 1C). ET-1 induced the release of big-ET-1 (the inactive ET-1 precursor) after 3-8 h of stimulation, and this effect was completely blocked by pretreatment with bosentan (fig 1D,E). ET-1induced ET-1 transcription was completely blocked by BQ123, a highly selective $\mathrm{ET}_{\mathrm{A}} \mathrm{R}$ inhibitor, ${ }^{15}{ }^{27}$ but not by $\mathrm{BQ788}$ (fig $1 \mathrm{~F}, \mathrm{G}$ ), a highly selective $\mathrm{ET}_{\mathrm{B}} \mathrm{R}$ inhibitor, ${ }^{15}{ }^{27}$ demonstrating a predominant role for $\mathrm{ET}_{\mathrm{A}} \mathrm{R}$ in this process.

ET-1 at 1, 10 (data not shown) and $100 \mathrm{nM}$ (fig 2A) rapidly activated ERK-1/-2 after 5-30 min of stimulation in a concentration-independent manner. ET-1 transiently activated p38 
A

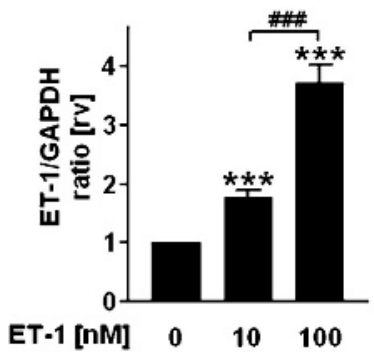

\section{B}

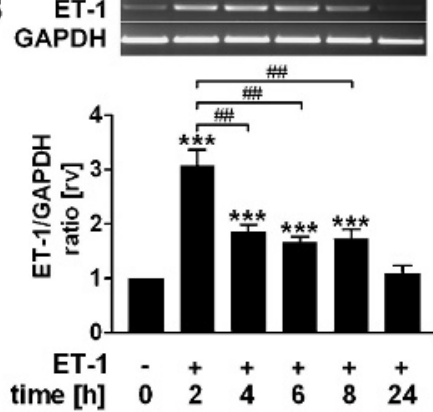

C

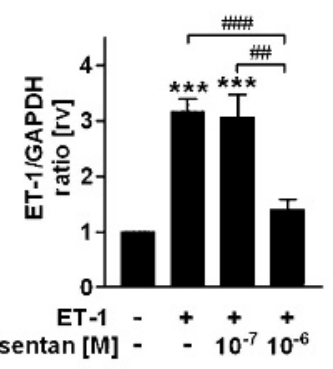

D

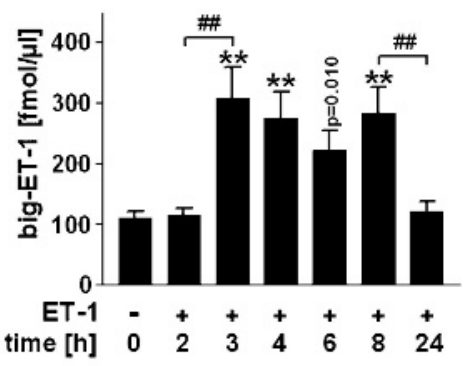

E

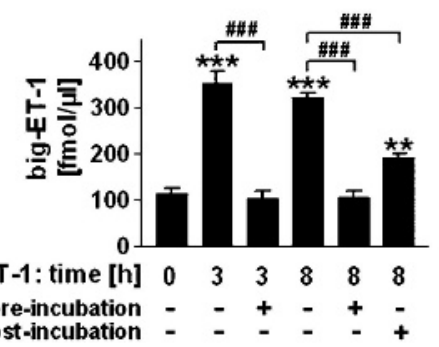

F

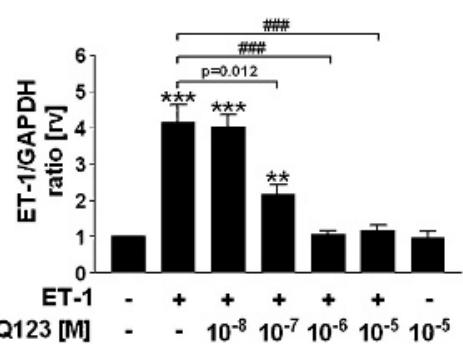

G

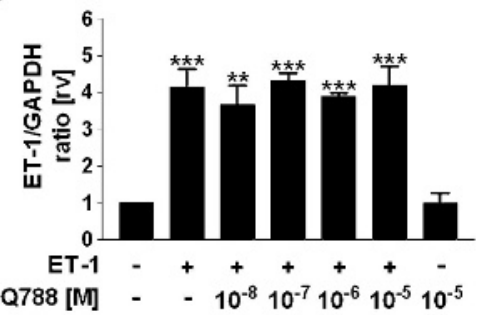

Figure 1 Endothelin-1 (ET-1) induces its own expression in human airway smooth muscle cells (HASMCs) via the enothelin receptor $\mathrm{ET}_{\mathrm{A}} \mathrm{R}$. $\mathrm{HASMCs}$ were stimulated with ET-1 at the indicated concentrations $(A)$ or at $100 \mathrm{nM}(B-G)$ for $2 \mathrm{~h}(\mathrm{~A}, \mathrm{C}, \mathrm{F}, \mathrm{G})$ or for the times indicated $(\mathrm{B}, \mathrm{D}, \mathrm{E})$. In $(\mathrm{C})$, $(\mathrm{F})$ and $(G)$ bosentan or selective inhibitors of $\mathrm{ET}_{\mathrm{A}} \mathrm{R}(\mathrm{B} 0123)$ or $\mathrm{ET}_{\mathrm{B}} \mathrm{R}(\mathrm{B0788)}$ were added to the medium $1 \mathrm{~h}$ before ET-1 stimulation at the concentrations indicated; in (E) bosentan at $10^{-6} \mathrm{M}$ was added at the times indicated before (pre-incubation) or after (post-incubation) ET-1 addition. (A-C, F, G) After incubation, the RNA was extracted and subjected to semi-quantitative reverse transcription-PCR (RT-PCR) with ET-1-specific primers. Glyceraldehyde phosphate dehydrogenase (GAPDH) was used as a standard. In (B, top) one representative example of a time-course set of RT-PCRs is shown. Semiquantitative RT-PCR signals were evaluated by densitometry. Values for ET-1 were normalised to GAPDH and related to solvent controls (0 nM, - ). (D, E) After incubation, concentrations of big-ET-1 in supernatants were measured by ELISA. Each graph represents the mean (SEM) of $n=4$ (E-G) or $\mathrm{n}=5(\mathrm{~A}-\mathrm{D})$ individual experiments. One-way repeated measures analysis of variance (ANOVA): $\mathrm{p}<0.0001$ (A-G). Post hoc Bonferroni-Holm tests: exact $p$ values down to 0.01 are indicated in the graph (related to the indicated values or to solvent controls if placed on top of a bar); ${ }^{* *} p<0.01$;

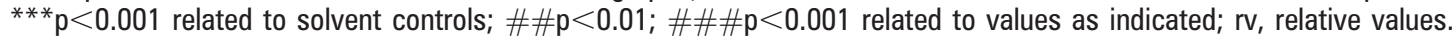

with four peak levels: after 5-30 min, and 2,4 and $6.5 \mathrm{~h}$ of stimulation (fig 2B). ET-1-induced ERK-1/-2 and p38MAPK activation was almost completely impaired by pretreatment with bosentan (fig 2C,D). In contrast to PD098059, a specific inhibitor of the ERK-1/-2 pathway, the p38 MAPK$_{\text {-specific }}$ inhibitor SB203580 almost completely inhibited ET-1-induced ET-1 transcription (fig 2E). These data provide evidence for an $\mathrm{ET}_{\mathrm{A}} \mathrm{R}$ - and p38 $^{\mathrm{MAPK}_{\text {-dependent }}}$ ET-1 autoregulatory positive feedback loop in HASMCs.

This hypothesis was supported by the following data: the exogenously added ET-1 was no longer detectable in the supernatant after $2 \mathrm{~h}$ of stimulation; however, we detected ET-1 $4 \mathrm{~h}$ after stimulation (Supplementary fig 1), indicating ET1 de novo synthesis. Postincubation with bosentan $3 \mathrm{~h}$ after ET1 stimulation reduced both the release of big-ET-1 after $8 \mathrm{~h}$ of ET-1 stimulation and the $4 \mathrm{~h}$ p38 $8^{\mathrm{MAPK}}$ activation peak (figs $1 \mathrm{E}$, $2 \mathrm{D})$. We conclude that the $4 \mathrm{~h}$ peak level results from the reactivation of p38 $8^{\text {MAPK }}$ through de novo synthesised ET-1 and contributes to the big-ET-1 expression observed after $8 \mathrm{~h}$ of stimulation and thus to the maintenance of big-ET-1 release (for a detailed discussion see Supplementary online material).

\section{$E T-1$ induces GM-CSF expression via $E_{A} R, E_{B} R$, ERK-1/-2 and p38 ${ }^{\mathrm{MAPK}}$ signalling}

In dose-response and time-response experiments ET-1 induced GM-CSF transcription in HASMCs at the highest level (five- to eightfold above the unstimulated control) at $100 \mathrm{nM}$ after $4 \mathrm{~h}$ of stimulation (fig $3 \mathrm{~A}, \mathrm{~B})$. Notably, the inducing effect on GMCSF transcription was detected at 2-8 h of stimulation (fig 3B). As individual treatments with bosentan, BO123, BO788, PD098059 and SB203580 all abolished ET-1-induced GM-CSF transcription (fig 3C-F) we conclude that ET-1 induces GMCSF expression via $\mathrm{ET}_{\mathrm{A}} \mathrm{R}, \mathrm{ET}_{\mathrm{B}} \mathrm{R}, \mathrm{ERK}-1 /-2$ and $\mathrm{p} 38^{\mathrm{MAPK}}$ signalling.

\section{TNF $\alpha$ induces ET-1 expression via $\mathrm{ET}_{\mathrm{A}} \mathrm{R}$ and $\mathrm{p} 38^{\mathrm{MAPK}}$}

TNF $\alpha$ did not influence ET-1 mRNA levels at $1 \mathrm{ng} / \mathrm{ml}$ (data not shown). However, at $10 \mathrm{ng} / \mathrm{ml}$ (data not shown) and $20 \mathrm{ng} / \mathrm{ml}$, TNF $\alpha$ (fig 4A) strongly induced ET-1 transcription after 2-8 h of stimulation without statistically significant differences between these concentrations and times. This effect was reduced by specific blocking of TNFR1 or TNFR2 (fig 4B). TNF $\alpha$ induced ET-1 release from HASMCs after 4-72 h of stimulation (fig 4C). Surprisingly, TNF $\alpha$-induced ET-1 transcription after $4 \mathrm{~h}$ and ET-1 release after $6 \mathrm{~h}$ were both partially blocked by bosentan (fig 4D,E). TNF $\boldsymbol{\alpha}$-induced ET-1 transcription was also reduced by BO123 but not by BO788 (fig $4 \mathrm{~F}, \mathrm{G}$ ).

$\mathrm{TNF} \alpha$ activated ERK-1/-2 at 1,20 and $50 \mathrm{ng} / \mathrm{ml}$ (fig $5 \mathrm{~A}$, data not shown) after 5-30 min of stimulation in a concentrationindependent manner. TNF $\alpha$ activated $\mathrm{p} 38^{\mathrm{MAPK}}$ at three time peaks: after 5-45 min, and after 5 and $9 \mathrm{~h}$ of stimulation (fig 5B). Bosentan did not significantly reduce ERK-1/-2-or p38 $8^{\mathrm{MAPK}}$ activation in response to $15 \mathrm{~min}$ TNF $\alpha$ stimulation (data not shown). TNF $\alpha$-induced ET-1 transcription was almost 
A

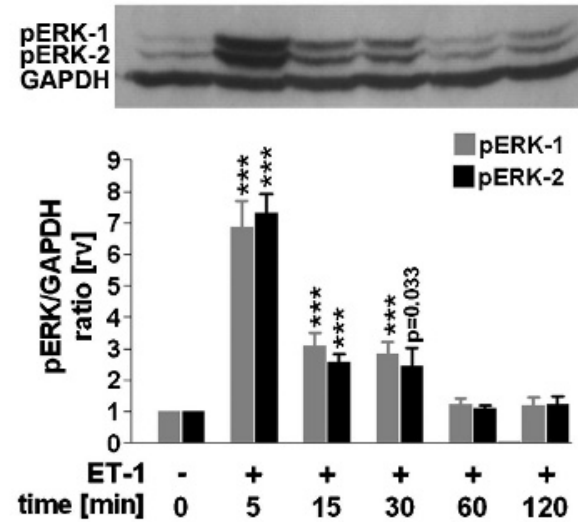

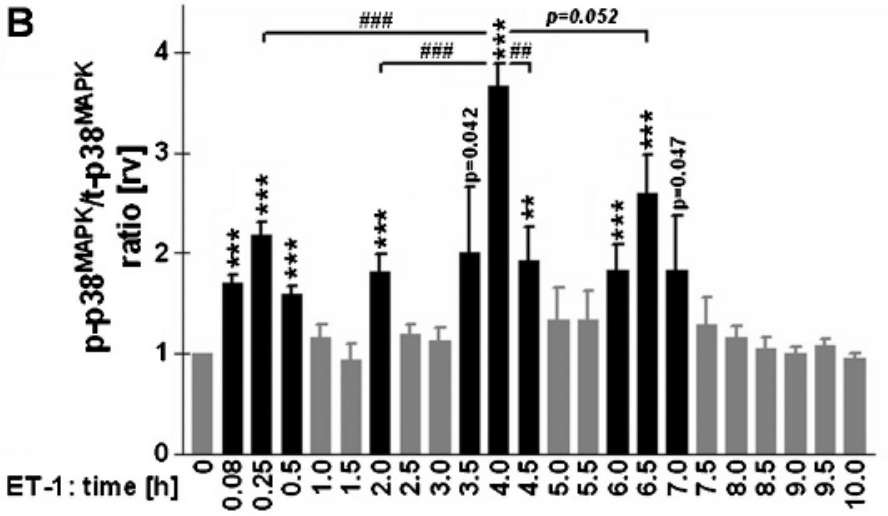
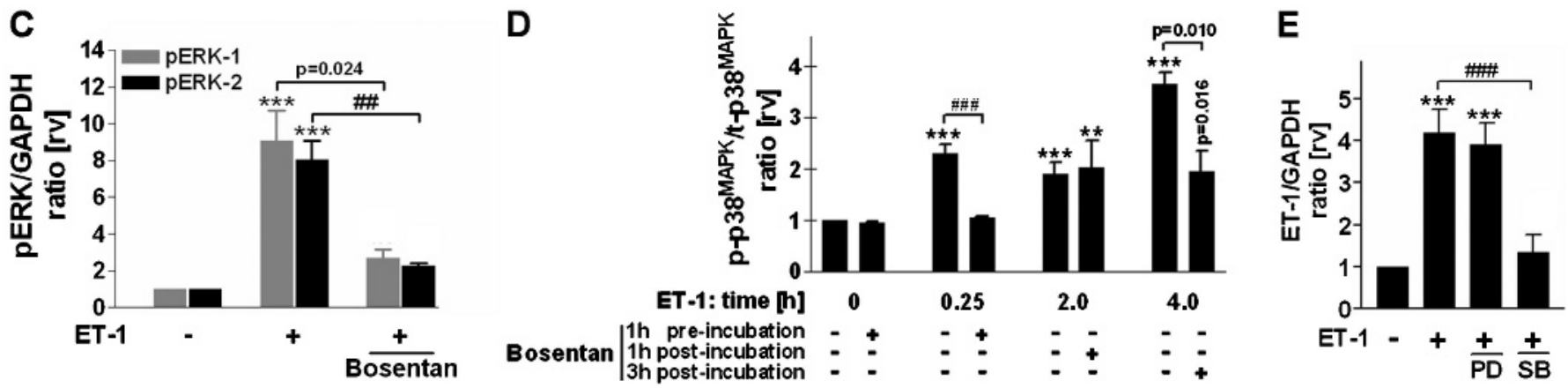

Figure 2 The endothelin-1 (ET-1) autoregulatory positive feedback loop depends on p38 mitogen-activated protein kinase (p38 ${ }^{\text {MAPK }}$ ). Human airway smooth muscle cells (HASMCs) were stimulated with ET-1 at $100 \mathrm{nM}$ for the indicated times (A, B, D), for 5 min (C) or for $2 \mathrm{~h}(\mathrm{E})$. Bosentan at $10^{-6} \mathrm{M}$ was added to the medium $1 \mathrm{~h}$ before ET-1 stimulation (C) or at the times indicated before (pre-incubation) or after (post-incubation) ET-1 addition (D). In (E) PD098059 $(10 \mu \mathrm{M})$ or SB203580 $(10 \mu \mathrm{M})$ was added 30 min before ET-1 stimulation. (A, C) After incubation, proteins were extracted and subjected to quantitative immunodetection of activated phosphorylated extracellular signal-regulated kinase-1/-2 (pERK-1/-2) with a pERK-1/-2-specific antibody. Glyceraldehyde phosphate dehydrogenase (GAPDH) was used as a standard. (B, D) After incubation, the activity of p38 ${ }^{\mathrm{MAPK}}$ was measured by an intracellular ELISA for phosphorylated $p 38^{\text {MAPK }}$ ( $p-p 38^{\text {MAPK}}$ ) with total p38 $8^{\text {MAPK }}$ ( $t-p 38^{\text {MAPK }}$ ) as a reference. (E) After incubation, the RNA was extracted and subjected to semi-quantitative reverse transcription-PCR (RT-PCR) with ET-1-specific primers. GAPDH was used as a standard. Semi-quantitative RT-PCR signals were evaluated by densitometry. Values for pERK-1/-2 and ET-1 or for p-p38 ${ }^{\text {MAPK }}$ were normalised to GAPDH or to t-p38 $8^{\text {MAPK }}$, respectively, and related to solvent controls $(0 \mathrm{~h},-)$. Each graph represents the mean (SEM) of $n=4(B, D), n=5(E), n=6(C)$ or $n=7(A)$ individual experiments. One-way repeated measures analysis of variance (ANOVA): $p<0.0001$ ( $A, B, D, E) ; p=0.0014(C, E R K-1) ; p=0.0001(C, E R K-2)$. Post hoc Bonferroni-Holm tests: exact p values down to 0.01 are indicated in the graph (related to the indicated values or to solvent controls if placed on top of a bar); ${ }^{* *} p<0.01 ;{ }^{* *} p<0.001$ related to solvent controls; in (B) statistically significant upregulations compared with the solvent control are indicated by black bars; \#\#p $<0.01$; \#\#\#p $<0.001$ related to values as indicated; rv, relative values.

completely blocked by SB203580 (fig 5C) but not by PD098059 (data not shown). Thus, our data demonstrate that TNF $\alpha$ induced ET-1 transcription depends on $\mathrm{ET}_{\mathrm{A}} \mathrm{R}$ and $\mathrm{p} 38^{\mathrm{MAPK}}$ signalling.

\section{TNF $\alpha$ induces GM-CSF release via activation of endothelin signalling}

TNF $\alpha$ induced GM-CSF transcription at two peak levels: after 2 and $8-12 \mathrm{~h}$ of stimulation (fig $6 \mathrm{~A}$ ). Whereas the $2 \mathrm{~h}$ peak was completely reduced by specific blocking of TNFR1 but not of TNFR2, the $8 \mathrm{~h}$ peak was partially reduced by individual blocking of both receptor subtypes (fig 6B,C). Bosentan did not modulate GM-CSF transcription after $2 \mathrm{~h}$ of TNF $\alpha$ stimulation; however, the drug clearly impaired the induction of GM-CSF transcription after $8 \mathrm{~h}$ of TNF $\alpha$ stimulation (fig 6D). Both BQ123 and BO788 individually blocked TNF $\alpha$-induced GM-CSF transcription after $8 \mathrm{~h}$ with an efficiency similar to bosentan (fig $6 \mathrm{E}, \mathrm{F}$ ). This indicates that unlike the short-term effect, the long-term effect of TNF $\alpha$ on GM-CSF expression depends on the activation of each endothelin receptor subtype.

TNF $\alpha$ induced a strong GM-CSF release after $72 \mathrm{~h}$, and this effect was reduced by $\sim 65 \%$ by bosentan (fig $6 \mathrm{G}$ ). TNF $\alpha$-induced GM-CSF release was also partially reduced by PD098059 and completely impaired by SB203580 (fig 6G). The combined treatment of TNF $\alpha$-stimulated HASMCs with bosentan and PD098059 did not result in an additional reduction of GM-CSF expression compared with the individual treatments (fig $6 \mathrm{G}$ ). These data demonstrate that TNF $\alpha$-induced GM-CSF release is mediated by ERK-1/-2 and p38MAPK signalling, and depends, at least in part, on endothelin receptor activity.

\section{DISCUSSION}

We found that ET-1 rapidly induces its own expression in HASMCs, suggesting an ET-1 autoregulatory positive feedback loop (fig 7). In contrast to blocking $\mathrm{ET}_{\mathrm{B}} \mathrm{R}$ and ERK-1/-2, inhibiting $\mathrm{ET}_{\mathrm{A}} \mathrm{R}$ and $\mathrm{p} 38^{\mathrm{MAPK}}$ activity almost completely 
A

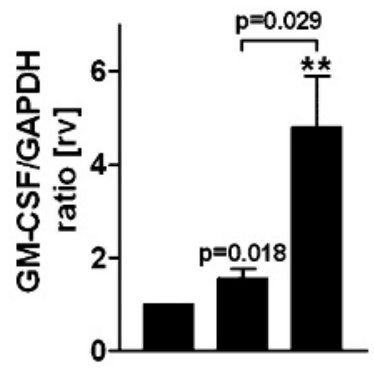

$E T-1[n M] \quad 0 \quad 10 \quad 100$
B

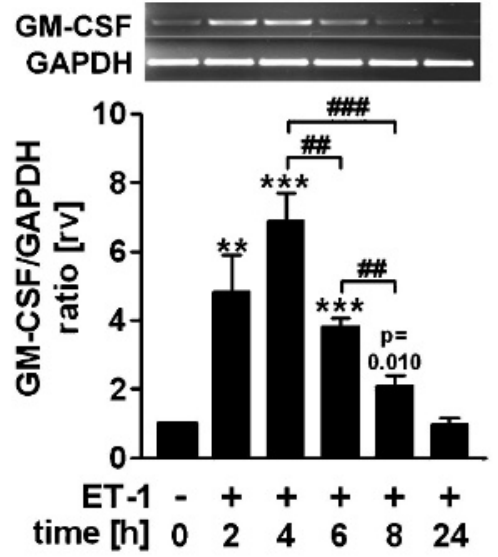

C

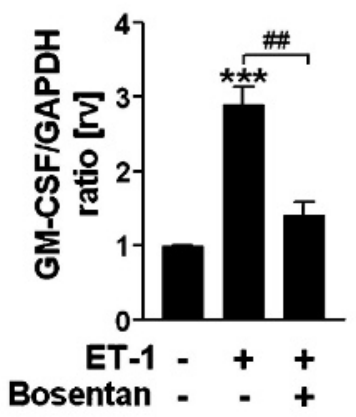

$\mathbf{F}$

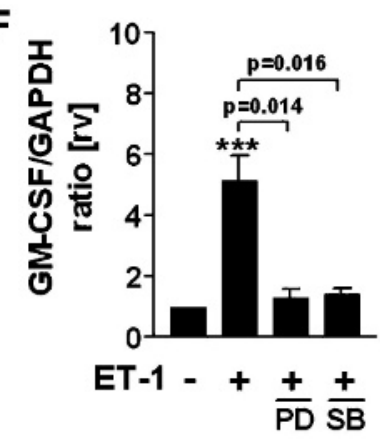

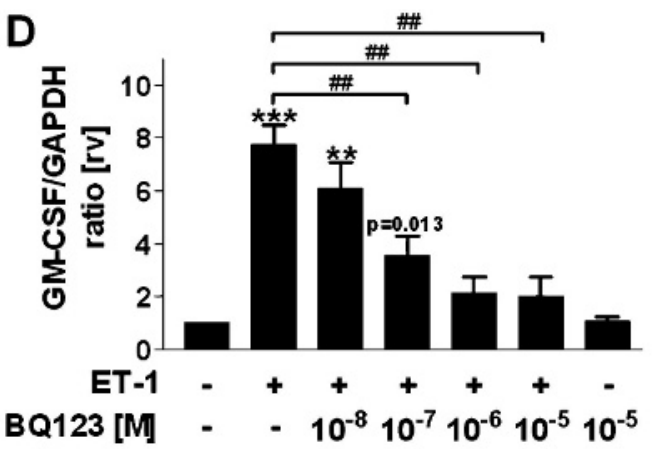

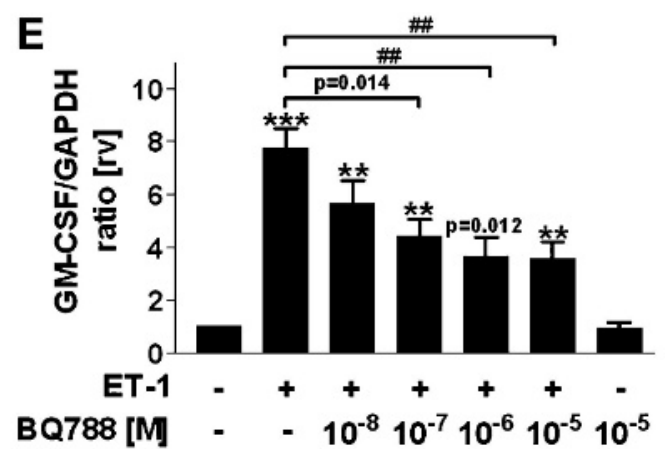

Figure 3 Endothelin-1 (ET-1) induces granulocyte-macrophage colony-stimulating factor (GM-CSF) expression in human airway smooth muscle cells (HASMCs) via the endothelin receptors $\mathrm{ET}_{\mathrm{A}} \mathrm{R}$ and $\mathrm{ET}_{\mathrm{B}} \mathrm{R}$, extracellular signal-regulated kinase (ERK)-1/-2 and p38 mitogen-activated protein kinase (p38 $\left.{ }^{\mathrm{MAPK}}\right)$. HASMCs were stimulated with ET-1 at the indicated concentrations $(\mathrm{A})$ or at $100 \mathrm{nM}(\mathrm{B}-\mathrm{F})$ for $4 \mathrm{~h}(\mathrm{~A}, \mathrm{C}-\mathrm{F})$ or for the indicated times $(\mathrm{B})$. In (C) bosentan at $10^{-6} \mathrm{M}$ and in (D) and (E) selective inhibitors of $E T_{A} R(B 0123)$ or $E T_{B} R(B 0788)$ at the indicated concentrations were added to the medium $1 \mathrm{~h}$ before ET-1 stimulation. In (F) PD098059 (10 $\mu \mathrm{M})$ or SB203580 (10 $\mu \mathrm{M})$ was added 30 min before ET-1 stimulation. After incubation, the RNA was extracted and subjected to semi-quantitative reverse transcription-PCR (RT-PCR) with GM-CSF-specific primers. Glyceraldehyde phosphate dehydrogenase (GAPDH) was used as a standard. In (B, top) one representative example of a time-course set of RT-PCRs is shown. Semi-quantitative RT-PCR signals were evaluated by densitometry. Values for GM-CSF were normalised to GAPDH and related to solvent controls (0 nM, - ). Each graph represents the mean (SEM) of $n=4(D-F)$ or $n=5(A-C)$ individual experiments. One-way repeated measures analysis of variance (ANOVA):

$p=0.0029(A) ; p<0.0001(B-F)$. Post hoc Bonferroni-Holm tests: exact $p$ values down to 0.01 are indicated in the graph (related to the indicated

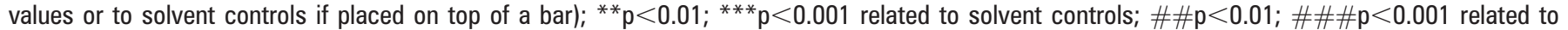
values as indicated; rv, relative values.

impaired ET-1-induced ET-1 transcription, demonstrating that activation of the $\mathrm{ET}_{\mathrm{A}} \mathrm{R} / \mathrm{p} 38^{\mathrm{MAPK}}$ pathway is necessary to initiate and/or maintain this ET-1 feedback mechanism (for further discussion, see the Supplementary online material). The induction of GM-CSF expression by ET-1 has been described for other cell types-for example, lung fibroblasts, ${ }^{16}$ but we were first able to demonstrate this ET-1 effect in HASMCs, thereby underlining ET-1 proinflammatory functions. In contrast to ET-1 autoregulation, its effect on GM-CSF transcription depends on the activation of both endothelin receptor subtypes and on p38MAPK and ERK-1/-2 pathways. Individual $\mathrm{ET}_{\mathrm{A}} \mathrm{R}$ or $\mathrm{ET}_{\mathrm{B}} \mathrm{R}$ blockade is sufficient to impair ET-1-induced GM-CSF transcription by $\sim 75 \%$ or $50 \%$, respectively, indicating that the combined activation of both receptor subtypes is required for maximum effects.

Here, we demonstrate for the first time that TNF $\alpha$ induces rapid ET-1 transcription and release by HASMCs. In a rat model of airway inflammation, increased ET-1 release in the lungs was observed after $3 \mathrm{~h}$ of provocation prior to the main inflammatory response. ${ }^{28}$ Since both TNF $\alpha$ and ET-1 are suggested as initial cytokines in airway inflammation, ${ }^{78}$ ET-1 release by HASMCs in response to TNF $\alpha$ might be an initial event in the amplification of inflammation in the airways. Mechanistic insights have been described for cerebrovascular endothelial cells, where the effect of TNF $\alpha$ on ET-1 mRNA upregulation depends on the generation of reactive oxygen species and on the activation of ERK-1/-2, p38 $8^{\mathrm{MAPK}}$ and their common downstream target mitogen- and stress-activated protein kinase (MSK). ${ }^{29}$ Consistently, we have shown here the complete reduction of TNF $\alpha$-induced ET-1 transcription by a p38 $8^{\text {MAPK }}$-specific inhibitor, but, in contrast, that experimental blocking of ERK-1/-2 has no effect. This indicates that TNF $\alpha$ activates ET- 1 transcription in HASMCs via the p38MAPK/MSK rather than the ERK/MSK pathway. However, our data cannot rule out an MSK-independent signalling mechanism.

It has previously been described that TNF $\alpha$-induced GM-CSF release from HASMCs depends on the activation of the c-Jun Nterminal kinase pathway. ${ }^{23}$ We have extended these studies by demonstrating that ERK-1/-2 or p38 ${ }^{\text {MAPK }}$ blockade also impairs TNF $\alpha$-induced GM-CSF release, suggesting that all three 
A

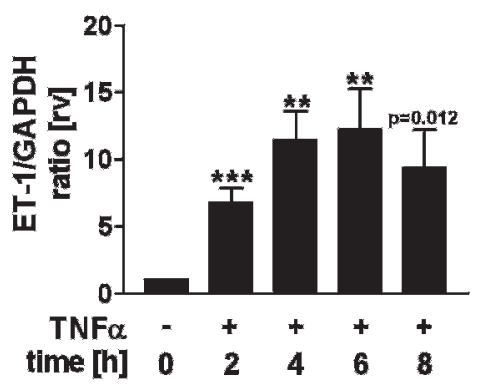

B

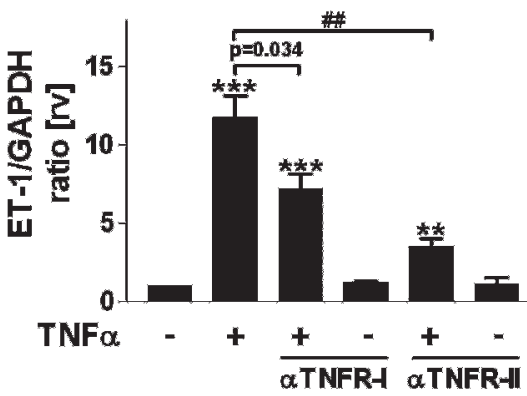

C

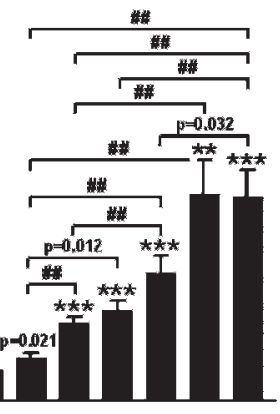

TNF $\alpha=++++++$

time [h] $\begin{array}{llllllll}0 & 4 & 6 & 8 & 24 & 48 & 72\end{array}$
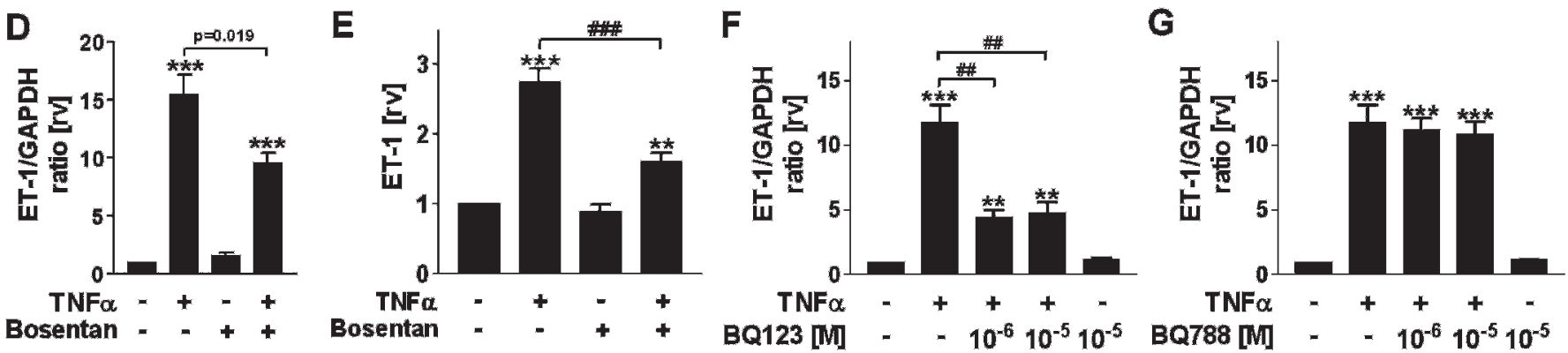

Figure 4 Tumour necrosis factor $\alpha$ (TNF $\alpha$ ) induces endothelin-1 (ET-1) expression in human airway smooth muscle cells (HASMCs) via the endothelin receptor $E_{A} R$. HASMCs were stimulated with human TNF $\alpha$ at $20 \mathrm{ng} / \mathrm{ml}$ for the indicated times $(\mathrm{A}, \mathrm{C})$ for $4 \mathrm{~h}(\mathrm{~B}, \mathrm{D}, \mathrm{F}, \mathrm{G})$ or for $6 \mathrm{~h}(\mathrm{E})$. (B) Monoclonal blocking antibodies specific for TNF receptor 1 (TNFR1; $\alpha$ TNFR-I, $10 \mu \mathrm{g} / \mathrm{ml}$ ) or TNFR2 ( $\alpha$ TNFR-II, $10 \mu \mathrm{g} / \mathrm{ml}$ ) were individually added to the medium 60 min prior to TNF $\alpha$ stimulation. Bosentan $\left(10^{-6} M\right)(D, E)$ or selective inhibitors for $E T_{A} R(B 0123)$ or $E T_{B} R$ (B0788) (at the indicated concentrations) $(F, G)$ were individually added to the medium $2 \mathrm{~h}$ prior to TNF $\alpha$ stimulation. $(A, B, D, F, G)$ After incubation, the RNA was extracted and subjected to semi-quantitative reverse transcription-PCR (RT-PCR) with ET-1-specific primers. Glyceraldehyde phosphate dehydrogenase (GAPDH) was used as a standard. Semi-quantitative RT-PCR signals were evaluated by densitometry. Values for ET-1 were normalised to GAPDH and related to solvent controls $(-)$. (C, E) After incubation, ET-1 concentrations in supernatants were measured by ELISA, and ET-1 values were normalised to solvent controls. A value of 1 corresponds on average to an ET-1 concentration of $0.45 \mathrm{fmol} / \mathrm{ml}$. Each graph represents the mean $(S E M)$ of $n=4(B, F, G)$ or $n=5(A, C-E)$ individual experiments. One-way repeated measures analysis of variance (ANOVA): $p=0.0069(A) ; p<0.0001$ (B-G). Post hoc Bonferroni-Holm tests: exact $p$ values down to 0.01 are indicated in the graph (related to the indicated values or to solvent controls if placed on top of a bar); ${ }^{* *} p<0.01$; ${ }^{* * *} \mathrm{p}<0.001$ related to solvent controls; \#\#p $<0.01$; \#\#\#p<0.001 related to values as indicated; rv, relative values.

prominent proinflammatory MAPK pathways are substantially involved in this process. We showed that TNF $\alpha$ induces GMCSF transcription at two peak levels after 2 and $8-12 \mathrm{~h}$ of stimulation. While the short-term effect depends exclusively on TNFR1, both TNFa receptor subtypes mediate the long-term effect and-notably-also TNF $\alpha$-induced ET-1 expression, indicating a link between these two signalling events. In addition, bosentan partially inhibited the long-term (but not the short-term) TNF $\alpha$ effect, demonstrating that endothelin receptor activity is necessary to obtain complete induction and/ or to maintain the complete level of GM-CSF expression in response to TNF $\alpha$. Consistently, bosentan reduced TNF $\alpha$ induced GM-CSF release from HASMCs.

These observations raise the question of a mechanistic link between TNF $\alpha$ and endothelin receptor activation. Since TNF $\alpha$ induces ET-1 release, and ET-1 induces its own expression and that of GM-CSF, we suggest the following model for the longterm effect of TNF $\alpha$ on GM-CSF expression: TNF $\alpha$ activates the ET-1 autoregulatory positive feedback loop by initial activation of the ET-1 gene via the p38 ${ }^{\mathrm{MAPK}}$ pathway. As a consequence, ET-1 autocrinally maintains the increased level of ET-1 expression via $\mathrm{ET}_{\mathrm{A}} \mathrm{R}$ and $\mathrm{p} 38^{\mathrm{MAPK}}$, and concurrently induces the expression and release of GM-CSF via both endothelin receptor subtypes and p38 $8^{\mathrm{MAPK}}$ and ERK-1/-2 signalling (fig 7). Our data demonstrating that blocking $\mathrm{ET}_{\mathrm{A}} \mathrm{R}$ (but not $\mathrm{ET}_{\mathrm{B}} \mathrm{R}$ ) activity attenuates TNF $\alpha$-induced ET-1 expression strongly support the hypothesis of an activation of the ET-1 feedback loop in response to TNF $\alpha$ (for a detailed discussion see the Supplementary online material). In contrast, the short-term TNF $\alpha$ effect on GM-CSF expression is bosentan insensitive and thus independent from endothelin signalling, and might include the canonical and rapid activation of MAPKs by TNFR1. This hypothesis is supported by our data showing a rapid increase of p38MAPK and ERK-1/-2 activity as early as 5 min after TNF $\alpha$ stimulation.

HASMCs are believed to contribute to the establishment of inflammation in chronic inflammatory airway diseases and lung fibrosis, ${ }^{1}$ and our data suggest that this could be mediated by ET-1 and GM-CSF upregulation in response to pathogenically elevated TNF $\alpha$ levels. Accordingly, the inhibiting effects of bosentan on the TNF $\alpha /$ ET-1/GM-CSF network in HASMCs suggest therapeutic utility for bosentan in the treatment of inflammation in chronic inflammatory airway diseases and lung fibrosis, particularly in early stages. Maximal TNF $\alpha$-induced GM-CSF expression requires the activity of both $\mathrm{ET}_{\mathrm{A}} \mathrm{R}$ and $\mathrm{ET}_{\mathrm{B}} \mathrm{R}$, suggesting that a dual endothelin receptor blocker might 
A

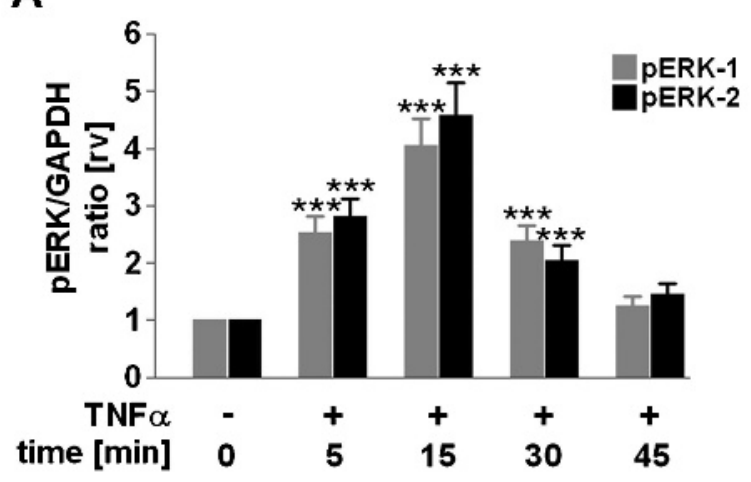

C

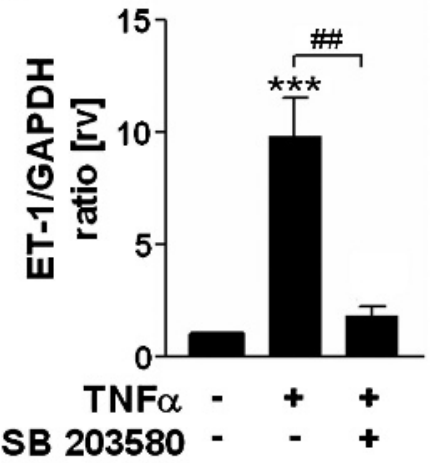

B

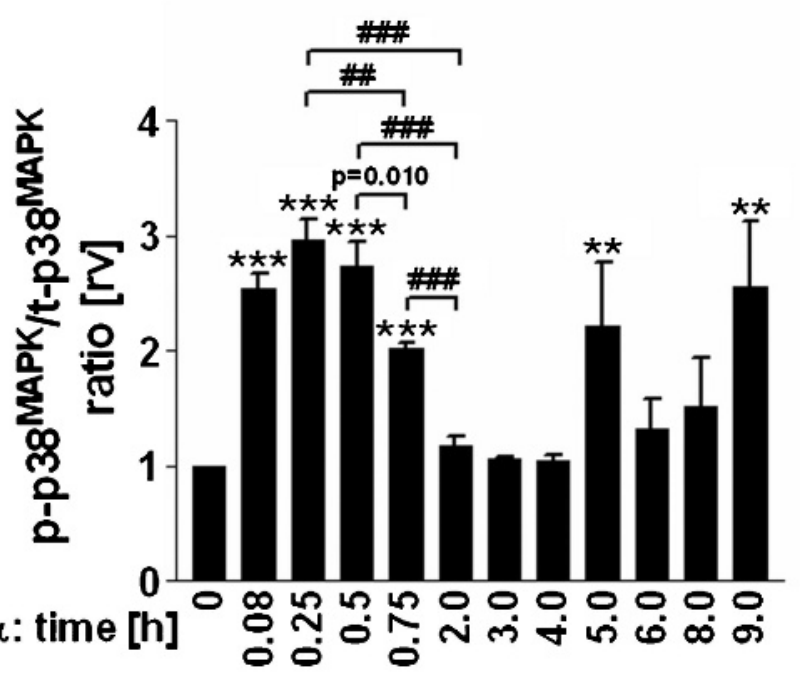

Figure 5 Tumour necrosis factor $\alpha$ (TNF $\alpha$ ) induces ET-1 expression in human airway smooth muscle cells (HASMCs) via p38 mitogen-activated protein kinase (p38 $8^{\text {MAPK }}$ ). HASMCs were stimulated with human TNF $\alpha$ at $20 \mathrm{ng} / \mathrm{ml}$ for the indicated times (A, B) or for $4 \mathrm{~h}$ (C). In (C) SB203580 $(10 \mu \mathrm{M})$ was added $30 \mathrm{~min}$ before TNF $\alpha$ stimulation. (A) After incubation, proteins were extracted and subjected to quantitative immunodetection of phosphorylated extracellular signal-regulated kinase-1/-2 (p-ERK-1/-2). Glyceraldehyde phosphate dehydrogenase (GAPDH) was used as a standard. (B) After incubation, the amount of phosphorylated (p-) p38 ${ }^{\text {MAPK }}$ was determined in relation to total (t-) p38 ${ }^{\text {MAPK }}$ by intracellular ELISA. (C) After incubation, the RNA was extracted and subjected to semi-quantitative reverse transcription-PCR (RT-PCR) with ET-1-specific primers. GAPDH was used as a standard. Semi-quantitative RT-PCR signals were evaluated by densitometry. Values for pERK-1/-2, p-p38 $8^{\text {MAPK }}$ or ET-1 were normalised to GAPDH (A, C) or to t-p38 ${ }^{\text {MAPK }}(B)$, respectively, and related to solvent controls $(0 h,-)$. Each graph represents the mean $(S E M)$ of $n=5(B, C)$ or $n=7(A)$ individual experiments. One-way repeated measures analysis of variance (ANOVA): $p<0.0001$ (A-C, in A values for ERK-1 and ERK-2 were analysed separately). Post hoc Bonferroni-Holm tests: exact $p$ values down to 0.01 are indicated in the graph; ${ }^{* *} p<0.01 ;{ }^{* *} p<0.001$ related to solvent controls; $\# \# \mathrm{p}<0.01$; \#\#\#p<0.001 related to values as indicated; rv, relative values.

be advantageous in therapy over selective blockers. The current study was designed to elucidate a novel signalling pathway with relevance for airway inflammation in order to provide a basis for developing new therapeutic strategies. The efficiency of dual versus selective endothelin receptor antagonists available for therapy in inhibiting the TNF $/$ ET-1/GM-CSF network or other inflammatory/profibrotic cytokines whose expression is mediated by TNF $\alpha / E T-1$ has to be deciphered in further studies.

The BUILD-1 study evaluated the efficacy of bosentan in IPF. Bosentan was associated with a trend toward delayed time to disease progression or death, and improvement in quality of life, both of which were more pronounced (and reached statistical significance in a post hoc analysis) in a subgroup of patients with a biopsy-confirmed IPF diagnosis. ${ }^{19}$ These observations are currently being investigated in the BUILD-3 trial. Our data suggest that this beneficial effect of bosentan might be a result of antagonising airway inflammation associated with the TNF $\alpha / E T-1 / G M-C S F$ network.

In summary, we demonstrated that TNF $\alpha$ induces GM-CSF release in HASMCs via the activation of an ET-1 autoregulatory positive feedback loop. Moreover, we provided evidence for the anti-inflammatory properties of the dual receptor antagonist bosentan in HASMCs, and our data predict therapeutic utility for bosentan in the treatment of chronic inflammatory airway diseases and lung fibrosis in the early stages. In this context, treatment with bosentan might be an auspicious therapy helping to reduce the application of high doses of corticosteroids and other immunmodulatory drugs. Furthermore, treatment with bosentan in early disease stages might be useful to avoid the induction of pulmonary hypertension as a late and serious complication of chronic inflammatory airway diseases and lung fibrosis. 

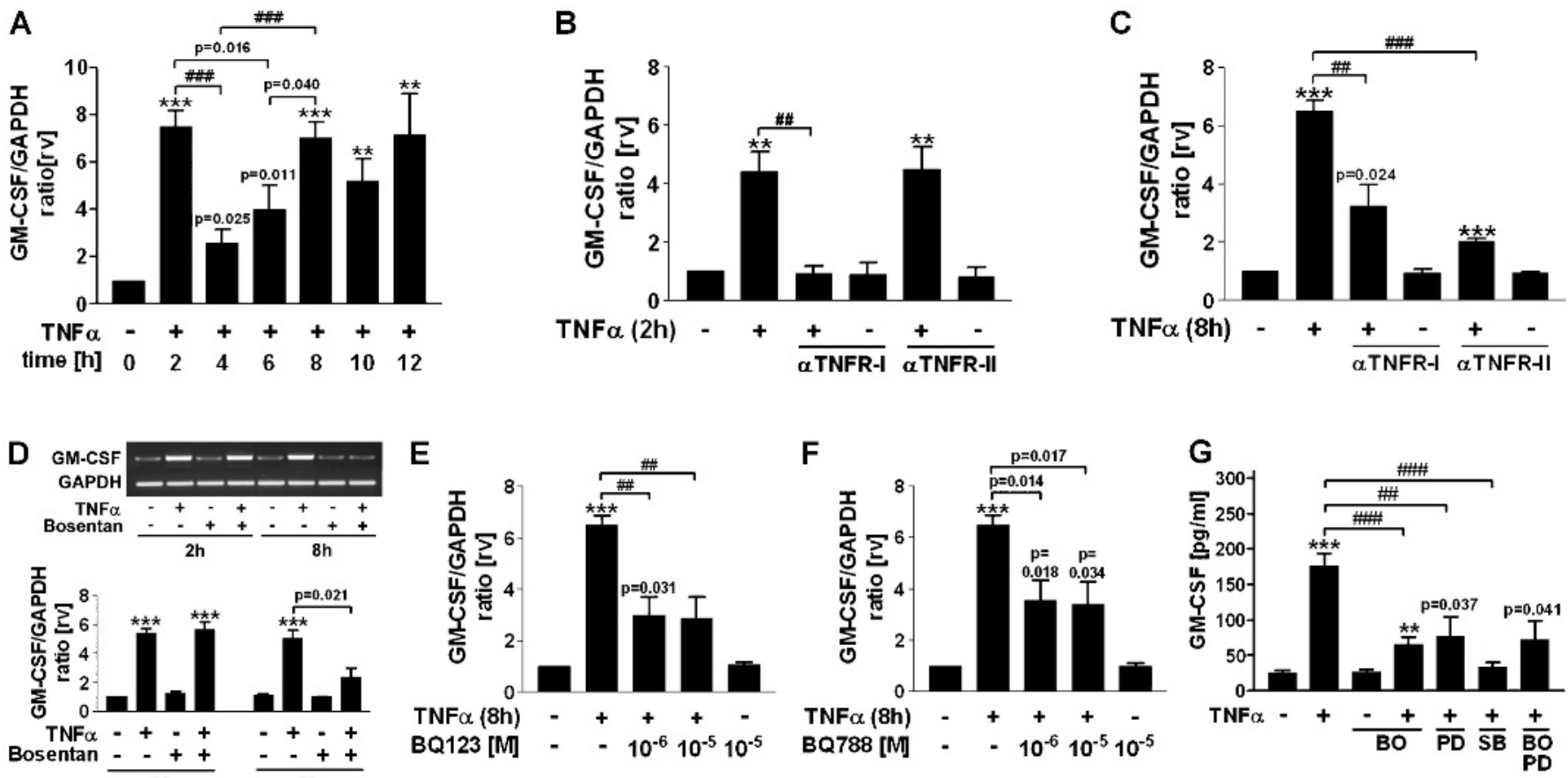

Figure 6 The maintenance of tumour necrosis factor $\alpha$ (TNF $\alpha$ )-induced granulocyte-macrophage colony-stimulating factor (GM-CSF) expression depends on signalling through TNF receptor 1 (TNFR1) and 2, endothelin receptors $E T_{A} R$ and $E T_{B} R$, and p38 mitogen-activated protein kinase (p38 ${ }^{\text {MAPK }}$ ) and extracellular signal-regulated kinase (ERK)-1/-2. Human airway smooth muscle cells (HASMCs) were stimulated with human TNF $\alpha$ at $20 \mathrm{ng} / \mathrm{ml}$ for the indicated times (A-F) or for $72 \mathrm{~h}(\mathrm{G})$. In (B) and (C) monoclonal blocking antibodies specific for TNFR1 ( $\alpha$ TNFR-I, $10 \mu \mathrm{g} / \mathrm{ml})$ or TNFR2 ( $\alpha$ TNFR-II, $10 \mu \mathrm{g} / \mathrm{ml}$ ) were individually added to the medium 60 min prior to TNF $\alpha$ stimulation. Bosentan $\left(B 0 ; 10^{-6} \mathrm{M}\right)(\mathrm{D}, \mathrm{G})$ or selective inhibitors for $\mathrm{ET}_{\mathrm{A}} \mathrm{R}$ (B0123) or $E T_{B} R$ (B0788) (at the indicated concentrations) (E, F) were individually added to the medium 2 h prior to TNF $\alpha$ stimulation. In (G) PD098059 $(10 \mu \mathrm{M})$ or SB203580 $(10 \mu \mathrm{M})$ were added 30 min before TNF $\alpha$ stimulation. (A-F) After incubation the RNA was extracted and subjected to semiquantitative reverse transcription PCR (RT-PCR) with GM-CSF-specific primers. Glyceraldehyde phosphate dehydrogenase (GAPDH) was used as a standard. One representative example of a set of RT-PCRs is shown in (D, top). Semi-quantitative RT-PCR signals were evaluated by densitometry. Values for GM-CSF were normalised to GAPDH and related to solvent controls (-). (G) After incubation the absolute amounts of GM-CSF protein in supernatants were determined by ELISA. Each graph represents the mean (SEM) of $n=4(B-F), n=5(A)$ or $n=9(G)$ individual experiments. Oneway repeated measures analysis of variance (ANOVA): $p<0.0001(A, C, D$ (values for $2 \mathrm{~h}$ and $8 \mathrm{~h}$ were analysed separately), $E, G) ; p=0.0001(B, F)$. Post hoc Bonferroni-Holm tests: exact p values down to 0.01 are indicated in the graph (related to the indicated values or to solvent controls if placed on top of a bar); ${ }^{* *} p<0.01 ;{ }^{* *} p<0.001$ related to solvent controls; $\# \# p<0.01$; $\# \# \# p<0.001$; related to values as indicated; rv, relative values.

Figure 7 Model to explain the involvement of endothelin signalling in tumour necrosis factor $\alpha$ (TNF $\alpha$ )-induced granulocyte-macrophage colonystimulating factor (GM-CSF) expression and release. TNF $\alpha$ is purposed initially to activate the enothelin-1 (ET-1) gene via the p38 mitogen-activated protein kinase (p38 ${ }^{\mathrm{MAPK}}$ ) pathway (indicated in black). As a consequence, the ET-1 autoregulatory positive feedback loop (indicated in blue) is activated, which depends on the endothelin receptor $\mathrm{ET}_{\mathrm{A}} \mathrm{R}$ and $\mathrm{p} 38^{\mathrm{MAPK}}$. In turn, elevated ET-1 levels induce and maintain GM-CSF expression and release via $\mathrm{ET}_{A} \mathrm{R}, \mathrm{ET}_{\mathrm{B}} \mathrm{R}, \mathrm{p} 38^{\mathrm{MAPK}}$ and extracellular signal-regulated protein kinase (ERK)-1/-2 (indicated in green). The individual impact of the endothelin receptor subtypes on the activation of $\mathrm{p} 38^{\mathrm{MAPK}}$ and ERK-1/-2 signalling is unclear (indicated by question marks). Inhibition of endothelin receptor activity by bosentan (indicated in red) impairs the long-term effect of TNF $\alpha$ on GM-CSF expression.

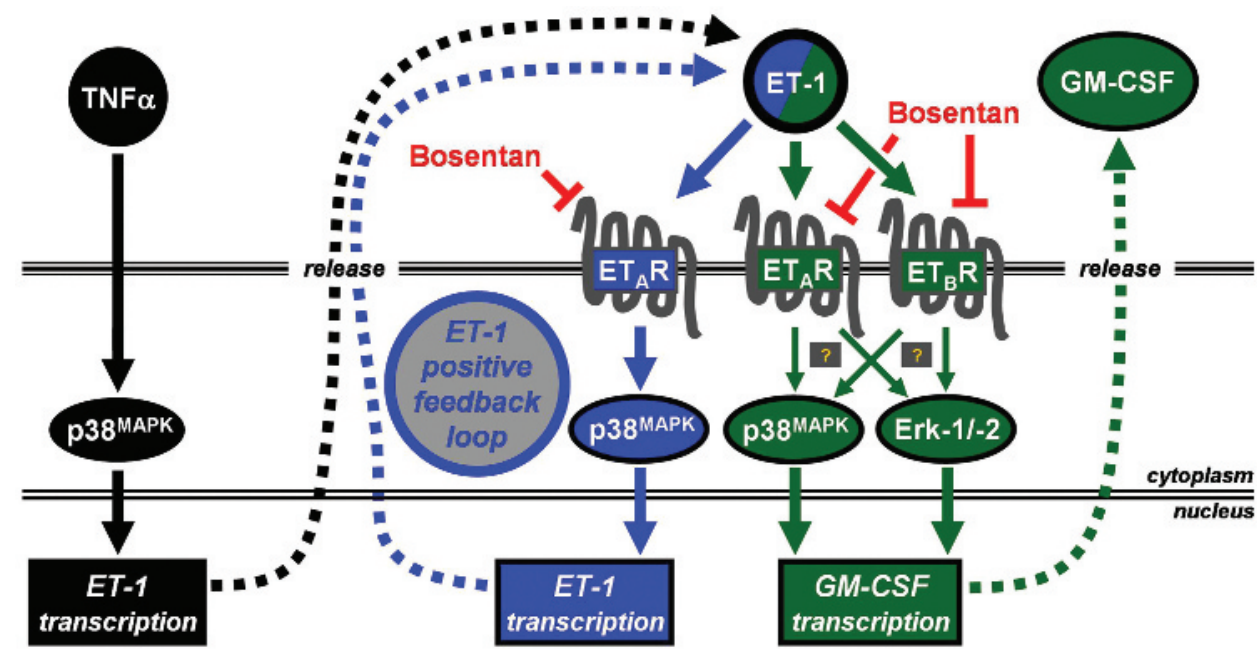


Acknowledgements: We thank Kerstin Reimann (IUF, Heinrich-Heine-University, Düsseldorf, Germany) for help with the p38 ${ }^{\mathrm{MAPK}}$ ELISA.

Funding: We thank Actelion Pharmaceuticals, Germany for their financial support. Actelion Pharmaceuticals were not involved in study design; in the collection, analysis, and interpretation of data; in the writing of the report; or in the decision to submit the paper for publication.

Competing interests: None.

Ethics approval: This study has been approved by the ethics committee of the University of Cologne, Cologne, Germany.

Provenance and peer review: Not commissioned; externally peer reviewed.

\section{REFERENCES}

1. Tliba $\mathbf{0}$, Panettieri RA Jr. Regulation of inflammation by airway smooth muscle. Curr Allergy Asthma Rep 2008;8:262-8.

2. Bringardner BD, Baran CP, Eubank TD, et al. The role of inflammation in the pathogenesis of idiopathic pulmonary fibrosis. Antioxid Redox Signal 2008;10:287-301.

3. Pohunek P. Inflammation and airway remodeling. Pediatr Pulmonol 2004;26:S98-9.

4. Chung KF. Inflammatory mediators in chronic obstructive pulmonary disease. Curr Drug Targets Inflamm Allergy 2005;4:619-25.

5. Thomas PS. Tumor necrosis factor-alpha: the role of this multifunctional cytokine in asthma. Immunol Cell Biol 2001;79:132-40.

6. Bonfield TL, Panuska JR, Konstan MW, et al. Inflammatory cytokines in cystic fibrosis lungs. Am J Respir Crit Care Med 1995;152:2111-8.

7. Lukacs NW, Strieter RM, Chensue SW, et al. TNF-alpha mediates recruitment of neutrophils and eosinophils during airway inflammation. J Immunol 1995;154:5411-7.

8. Amrani Y, Ammit AJ, Panettieri RA Jr. Tumor necrosis factor receptor (TNFR) 1, but not TNFR2, mediates tumor necrosis factor-alpha-induced interleukin-6 and RANTES in human airway smooth muscle cells: role of p38 and p42/44 mitogen-activated protein kinases. Mol Pharmacol 2001;60:646-55

9. Saunders MA, Mitchell JA, Seldon PM, et al. Release of granulocyte-macrophage colony stimulating factor by human cultured airway smooth muscle cells: suppression by dexamethasone. Br J Pharmacol 1997;120:545-6.

10. Xing Z, Braciak T, Ohkawara Y, et al. Gene transfer for cytokine functional studies in the lung: the multifunctional role of GM-CSF in pulmonary inflammation. J Leukoc Biol 1996;59:481-8.

11. Gajewska BU, Wiley RE, Jordana M. GM-CSF and dendritic cells in allergic airway inflammation: basic mechanisms and prospects for therapeutic intervention. Curr Drug Targets Inflamm Allergy 2003;2:279-92.

12. Yamashita $\mathbf{N}$, Tashimo $\mathrm{H}$, Ishida $\mathrm{H}$, et al. Attenuation of airway hyperresponsiveness in a murine asthma model by neutralization of granulocyte-macrophage colonystimulating factor (GM-CSF). Cell Immunol 2002;219:92-7.
13. Su YC, Rolph MS, Hansbro NG, et al. Granulocyte-macrophage colony-stimulating factor is required for bronchial eosinophilia in a murine model of allergic airway inflammation. J Immunol 2008;180:2600-7.

14. Vlahos R, Bozinovski S, Hamilton JA, et al. Therapeutic potential of treating chronic obstructive pulmonary disease (COPD) by neutralising granulocyte macrophagecolony stimulating factor (GM-CSF). Pharmacol Ther 2006;112:106-15.

15. Goldie RG. Endothelin receptor subtypes: distribution and function in the lung. Pulm Pharmacol Ther 1998;11:89-95.

16. Teder $\mathbf{P}$, Noble PW. A cytokine reborn? Endothelin-1 in pulmonary inflammation and fibrosis. Am J Respir Cell Mol Biol 2000;23:7-10.

17. Chalmers GW, Macleod KJ, Sriram S, et al. Sputum endothelin-1 is increased in cystic fibrosis and chronic obstructive pulmonary disease. Eur Respir J 1999;13:1288-92.

18. Zietkowski Z, Skiepko R, Tomasiak MM, et al. Endothelin-1 in exhaled breath condensate of stable and unstable asthma patients. Respir Med 2008:102:470-4.

19. King TE Jr. Bosentan for idiopathic pulmonary fibrosis. Curr Opin Investig Drugs 2008;9:1171-9.

20. Dupuis $\mathbf{J}$, Hoeper MM. Endothelin receptor antagonists in pulmonary arterial hypertension. Eur Respir J 2008;31:407-15.

21. Gamze K, Mehmet HM, Deveci F, et al. Effect of bosentan on the production of proinflammatory cytokines in a rat model of emphysema. Exp Mol Med 2007;39:614-20.

22. Finsnes $\mathbf{F}$, Skjønsberg $\mathrm{OH}$, Tønnessen $\mathrm{T}$, et al. Effect of endothelin antagonism on the production of cytokines in eosinophilic airway inflammation. Am J Physiol Lung Cell Mol Physiol 2001;280:L659-65.

23. Oltmanns U, Issa R, Sukkar MB, et al. Role of c-jun N-terminal kinase in the induced release of GM-CSF, RANTES and IL-8 from human airway smooth muscle cells. Br J Pharmacol 2003;139:1228-34.

24. Raidl M, Sibbing B, Strauch J, et al. Impaired TNFalpha-induced VEGF expression in human airway smooth muscle cells from smokers with COPD: role of MAPkinases and histone acetylation — effect of dexamethasone. Cell Biochem Biophys 2007:49:98-110.

25. Koch A, Knobloch J, Dammhayn C, et al. Effect of bacterial endotoxin LPS on expression of INF-gamma and IL-5 in T-lymphocytes from asthmatics. Clin Immunol 2007:125:194-204.

26. Koch A, Giembycz M, Ito K, et al. Mitogen-activated protein kinase modulation of nuclear factor-kappaB-induced granulocyte macrophage-colony-stimulating factor release from human alveolar macrophages. Am J Respir Cell Mol Biol 2004;30:342-9.

27. Hayasaki-Kajiwara Y, Naya N, Shimamura T, et al. Endothelin generating pathway through endothelin1-31 in human cultured bronchial smooth muscle cells. Br J Pharmacol 1999:127:1415-21.

28. Finsnes $\mathbf{F}$, Christensen $\mathrm{G}$, Lyberg $\mathrm{T}$, et al. Increased synthesis and release of endothelin-1 during the initial phase of airway inflammation. Am J Respir Crit Care Med 1998:158:1600-6.

29. Sury MD, Frese-Schaper M, Mühlemann MK, et al. Evidence that N-acetylcysteine inhibits TNF-alpha-induced cerebrovascular endothelin-1 upregulation via inhibition of mitogen- and stress-activated protein kinase. Free Radic Biol Med 2006;41:1372-83.

\section{BMJ Careers online re-launches}

BMJ Careers online has re-launched to give you an even better online experience. You'll still find our online services such as jobs, courses and careers advice, but now they're even easier to navigate and quicker to find.

New features include:

- Job alerts - you tell us how often you want to hear from us with either daily or weekly alerts

- Refined keyword searching making it easier to find exactly what you want

- Contextual display - when you search for articles or courses we'll automatically display job adverts relevant to your search

- Recruiter logos linked directly to their organisation homepage - find out more about the company before you apply

- RSS feeds now even easier to set up

Visit careers.bmj.com to find out more. 